\title{
PENGARUH LINGKUNGAN KERJA, PELATIHAN DAN KUALITAS PRODUK TERHADAP PRODUKTIVITAS KARYAWAN HOME INDUSTRY (KONVEKSI KERUDUNG) DI VILA COLLECTION LAREN LAMONGAN
}

\author{
Ike Susanti dan Indriana Kristiawati \\ Prodi Manajemen, Fakultas Ekonomi Universitas Islam Lamongan \\ email : ik33susanti@unisla.ac.id \\ indriana_k@yahoo.com
}

\begin{abstract}
ABSTRAK
Tujuan Penelitian ini adalah untuk mengetahuiPengaruh Lingkuangan Kerja, PelatihanDan Kualitas Produk Terhadap Produktifitas Karyawan Home Industri ( Konveksi Kerudung ) Di Villa Collection Laren Lamongan. Penelitian ini menggunakan metode kuantitatif, dengan menggunkan uji validitas dan reliabilitas, uji regresi berganda, uji koefisien korelasi, uji $t$ dan uji F. Hasil analisis dapat diketahui bahwa Uji t (Uji parsial) Variabel Lingkungan kerja (X1), nilai t hitung yang diperoleh adalah 6,376 dengan nilai signifikansinya sebesar 0,000, nilai ini lebih kecil dari pada $\alpha=0,05$,. Variabel Pelatihan(X2), nilai $t$ hitung yang diperoleh adalah 0,303 dengan nilai signifikansinya sebesar 0,763 nilai ini lebih besar dari pada $\alpha=$ 0,05,. Variabel Kualitas Produk (X3) nilai t hitung yang diperoleh adalah -2,609, dengan nilai signifikansinya 0,012 nilai ini kurang dari $\alpha=0,05$. Uji $F$ menunjukkan pengaruh yang signifikan dengan nilai $F_{\text {hitung }}$ lebih besar dari nilai $F_{\text {tabel }}$ 21,908 > 3,20 dengan tingkat signifikansi 0,000 > 0,05. Hasil Penelitian ini menunjukkan bahwa Lingkungan Kerja (X1), Pelatihan(X2), Kualitas Produk (X3) secara bersama/simultan berpengaruh terhadap Produktivitas Karyawan (Y). karena Lingkungan Kerja (X1) memiliki nilai korelasi parsial tertinggi yaitu sebesar 0,767 dibandingkan dengan variable Pelatihan(X2) dan Kualitas Produk (X3), maka variable Lingkungan Kerja (X1) merupakan variable bebas yang paling dominan mempengaruhi variable terikat yaitu Produktivitas Karyawan.
\end{abstract}

Kata kunci : Lingkungan Kerja, Pelatihan, Kualitas Produk dan produktivitas

\section{PENDAHULUAN}

Dalam lingkungan perusahaan jarang sekali memperhatikan masalah lingkungan kerja dan kenyamanan kerja padahal masalah lingkungan kerja dan kenyamanan kerja adalah suatu hal yang sangat utama, dengan lingkungan kerja yang aman, tenang dan tentram, maka orang yang bekerja akan bersemangat dan dapat bekerja secara baik sehingga hasil kerjanya pun memuaskan begitupun sebaliknya bila kondisi lingkungan kerja tidak baik maka dapat menurunkan produktivitas kerja karyawan. Demikian pula dengan masalah kenyamanan kerja, masalah kenyamanan kerja yang sangat baik akan membuat karyawan bekerja dengan baik karena para karyawan merasa nyaman dalam menjalankan tugasnya sehingga produktivitas kerja dapat dicapai secara maksimal, sebaliknya apabila lingkungan kerja kurang baik misalnya, peralatan produksi yang kurang memadai, penerangan yang kurang baik, serta kebersihan lingkungan kerja yang kurang memadai, akan mengakibatkan menurunnya produktivitas kerja karyawan. 
Keadaan lingkungan kerja yang baik akan memberikan dampak yang positif bagi karyawan dalam meningkatkan prestasi kerja karyawan. Hal itu merupakan salah satu cara yang dapat ditempuh agar karyawan dapat melaksanakan tugasnya tanpa mengalami gangguan, karena lingkungan kerja sangat mempengaruhi karyawan, lingkungan kerja yang baik dapat memacu produktivitas kerja karyawan yang tinggi.

Penciptaan lingkungan kerja dan kenyamanan kerja yang baik adalah salah satu bentuk upaya untuk menciptakan tempat kerja yang aman, sehat, bebas dari pencemaran lingkungan, sehingga dapat mengurangi dan atau bebas dari kecelakaan kerja dan penyakit akibat kerja yang pada akhirnya dapat meningkatkan efisiensi dan produktivitas kerja karyawan. Ruangan kerja akan terlihat sangat menyenangkan dan nyaman apabila seluruh karyawan dan pihak manajemen bisa saling menjaga keutuhan fasilitas yang tersedia dengan cara menjaga kebersihan, memperhatikan penerangan yang sudah ada dan juga merawat peralatan produksi yang tersedia, maka dapat tercipta lingkungan kerja dan kenyamanan kerja yang optimal.

\section{RUMUSAN MASALAH}

1. Apakah lingkungan kerja $\left(X_{1}\right)$, Pelatihan $\left(X_{2}\right)$ dan kualitas produk $\left(X_{3}\right)$ berpengaruh secara parsial terhadap produktivitas karyawan di Home Industry (konveksi kerudung) Vila Collection Laren Lamongan?

2. Apakah lingkungan kerja $\left(\mathrm{X}_{1}\right)$, Pelatihan $\left(\mathrm{X}_{2}\right)$ dan kualitas produk $\left(\mathrm{X}_{3}\right)$ berpengaruh secara simultan terhadap produktivitas karyawan di Home Industry (konveksi kerudung) Vila Collection Laren Lamongan?

3. Variabel manakah diantara lingkungan kerja $\left(\mathrm{X}_{1}\right)$, Pelatihan $\left(\mathrm{X}_{2}\right)$ dan kualitas produk $\left(\mathrm{X}_{3}\right)$ yang lebih dominan berpengaruh terhadap produktivitas karyawan di Home Industry (konveksi kerudung) Vila Collection Laren Lamongan?

\section{TUJUAN PENELITIAN}

1. Untuk mengetahui apakah faktor lingkungan kerja, Pelatihandan kualitas produk berpengaruh secara parsial terhadap produktivitas karyawan di Home Industry (konveksi kerudung) Vila Collection Laren Lamongan.

2. Untuk mengetahui apakah faktor lingkungan kerja, Pelatihandan kualitas produk berpengaruh secara simultan terhadap produktivitas karyawan di Home Industry (konveksi kerudung) Vila Collection Laren Lamongan.

3. Untuk mengetahui faktor lingkungan kerja, Pelatihandan kualitas produk mana yang lebih dominan berpengaruh terhadap produktivitas karyawan di Home Industry (konveksi kerudung) Vila Collection Laren Lamongan.

\section{LANDASAN TEORI}

\section{Pengertian Manajemen Produksi dan Operasi}

Menurut Handoko (2011:3) Manajemen produksi dan operasi merupakan usaha-usaha pengelolaan secara optimal penggunaan sumber daya-sumber daya (atau sering disebut faktofaktor produksi) tenaga kerja, mesin-mesin, peralatan, bahan mentah dan sebagainya - dalam 
proses transformasi bahan mentah dan tenaga kerja menjadi berbagai produk atau jasa. Para manajer produksi dan operasi mengarahkan berbagai masukan (input) agar dapat memproduksi berbagai keluaran (output) dalam jumlah, kualitas, harga, waktu dan tempat tertentu sesuai dengan permintaan konsumen.

\section{Lingkungan Kerja}

Lingkungan kerja adalah tempat dimana karyawan melakukan aktivitas setiap harinya. Lingkungan kerja yang kondusif memberikan rasa aman dan memungkinkan karyawan untuk dapat bekerja optimal. Lingkungan kerja dapat mempengaruhi emosi karyawan. Jika karyawan menyenangi lingkungan kerja dimana dia bekerja, maka karyawan tersebut akan betah ditempat kerjanya, melakukan aktivitas sehingga waktu kerja dipergunakan secara efektif. Lingkungan kerja itu mencakup hubungan kerja yang terbentuk antara sesama karyawan dan hubungan kerja antara bawahan dan atasan serta lingkungan fisik tempat karyawan bekerja.

Menurut Simanjuntak (2011:7) kondisi lingkungan kerja menyangkut jaminan kesehatan dan keselamatan kerja (K3). Jaminan K3 mencangkup kesehatan dan keselamatan pekerja dan setiap orang dilingkungan kerja, keselamatan aset dan alat-alat produksi, dan keselamatan hasil produksi sendiri. Kecelakaan kerja dapat mengakibatkan pekerja meninggal, sakit keras atau cacat sehingga tidak mampu bekerja untuk sekian lama. Kecelakaan kerja dapat mengakibatkan mesin rusak dan berhenti berproduksi, gedung rusak atau terbakar, sehingga produksi terhenti dalam waktu tertentu. Hal ini merugikan besar bagi perusahaan. Kecelakaan kerja dapat menimbulkan kerusakan hasil produksi, sehingga hasil keseluruhan menjadi tidak optimal.

\section{Pelatihan}

Pelatihan adalah proses sistematik pengubahan perilaku para karyawan dalam suatu arah guna meningkatkan tujuan-tujuan operasional (Simamora,2004:344). Pelatihan adalah usaha untuk pengembangan skill, pengetahuan, dan sikap-sikap pegawai atau anggota organisasi, wexley dan Yulk dalam Mangkunegara(2006:43). Pelatihan berkaitan dengan peningkatan kemampuan atau keterampilan karyawan yang sudah menduduki suatu pekerjaan atau tugas tertentu,Notoatmodjo(1998:26) Penekanan dalam suatu pelatihan adalah pada tugas yang akan dilaksanakan (job orientation). Disamping itu pelatihan pada umumnya menekankan kepada kemampuan psikomotor, meskipun didasari pengetahuan dan sikap. Hal inilah yang mendasari orientasi pelatihan kepada pelaksanaan tugas serta kemampuankemampuan khusus pada sasaran.

\section{Kualitas Produk}

Kualitas produk merupakan salah satu sarana positioning utama pemasar.kualitas memiliki dampak langsung pada kinerja produk atau jasa. Oleh karena itu, kualitas berhubungan erat dengan nilai dan kepuasan pelanggan.Dalam arti yang lebih sempit, kualitas produk dapat didevinisikan sebagai bebas dari kerusakan.Akan tetapi, sebagian besar 
perusahaan yang berpusat pada pelanggan, melangkah jauh melampaui devinisi sempit ini (Budiyono 2013:272).

\section{Produktivitas}

Menurut Handoko (2011:210) Produktivitas merupakan istilah dalam kegiatan produksi sebagai perbandingan antara luaran (output) dengan masukan (input). Produktivitas merupakan suatu ukuran yang menyatakan bagaimana baiknya sumber daya diatur dan dimanfaatkan untuk mencapai hasil yang optimal. Produktivitas dapat digunakan sebagai tolak ukur keberhasilan suatu industri dalam menghasilkan barang atau jasa.

Menurut Handoko (2011:213) Pengukuran produktivitas hanya merupakan langkah pertama dalam peningkatan produktivitas. Langkah kedua adalah pemahaman terhadap faktor-faktor yang mempengaruhi produktifitas dan memilih faktor-faktor peningkatan yang sesuai dengan situasi tertentu.

\section{HIPOTESIS}

$\mathrm{H} 1$ : Diduga bahwa lingkungan kerja $\left(\mathrm{X}_{1}\right)$, Pelatihan $\left(\mathrm{X}_{2}\right)$ dan kualitas produk $\left(\mathrm{X}_{3}\right)$ berpengaruh secara parsial terhadap produktivitas karyawan di Home Industry (konveksi kerudung) Vila Collection Laren Lamongan.

$\mathrm{H} 2$ : Diduga bahwa lingkungan kerja $\left(\mathrm{X}_{1}\right)$, Pelatihan $\left(\mathrm{X}_{2}\right)$ dan kualitas produk $\left(\mathrm{X}_{3}\right)$ berpengaruh secara simultan terhadap produktivitas karyawan di Home Industry (konveksi kerudung) Vila Collection Laren Lamongan.

$\mathrm{H} 3$. Diduga bahwa lingkungan kerja $\left(\mathrm{X}_{1}\right)$ lebih dominan berpengaruh secara signifikan terhadap produktivitas karyawan di Home Industry (konveksi kerudung) Vila Collection Laren Lamongan.

\section{METODE PENELITIAN}

Atas pertimbangan tujuan penelitian, maka penelitian ini bersifat statistik deskriptif. Statistik deskriptif adalah statistik yang digunakan untuk menganalisis data paling sederhana yang dilakukan untuk mendapatkan informasi lebih rinci dari satu kelompok data (Soedarmayanti, 2011:171).

\section{Teknik Penarikan Sampel}

1. Populasi

2. Sampel

3. TeknikSampling

\section{Metode Pengumpulan Data}

1. Wawancara

2. Kuesioner

3. Observasi

\section{Metode Analisis Data}




\section{Analisis Regresi Linear Berganda}

Teknik ini digunakan untuk menguji hipotesis yang menduga ada pengaruh antara variabel bebas terhadap variabel terikat adapun bentuk persamaannya adalah:

$\mathrm{Y}=\mathrm{a}+\mathrm{b}_{1} \mathrm{X}_{1}+\mathrm{b}_{2} \mathrm{X}_{2}$

Dimana:

$\mathrm{Y}=$ produktivitas karyawan

$\mathrm{b}=$ koefisien beta

$\mathrm{a}=$ koefisien konstanta

$\mathrm{X}_{1}=$ lingkungan kerja

$\mathrm{X}_{2}=$ Pelatihan

$\mathrm{X}_{3}=$ kualitas produk

\section{Analisis Korelasi Berganda}

Analisis ini digunakan untuk menguji signifikan tidaknya hubungan antara dua variabel berpasangan adapun rumus yang digunakan adalah:

Rumus :

Ry. $x_{1} x_{2}=\frac{\sqrt{r^{2} y x_{1}+r^{2} y x_{2}-2 r y x_{1} \cdot r y x_{2} \cdot r x_{1} x_{2}}}{1-r^{2} x_{1} x_{2}}$

$r_{y . x}=$ koefisien korelasi antara $\mathrm{y}$ dan $\mathrm{x}_{1}$

$r_{y . x 2}=$ koefisien korelasi antara $\mathrm{y}$ dan $\mathrm{x}_{2}$

$r_{x 1 . x 2}=$ koefisien korelasi antara $\mathrm{x}_{1}$ dan $\mathrm{x}_{2}$

\section{Uji t}

Uji t merupakan uji statistik yang sering kali ditemui dalam masalah-masalah praktik statistika. Uji t termasuk dalam golongan statistik parametik. Uji t digunakan ketika informasi mengenai nilai variance (ragam) populasi tidak diketahui (Sofyan, 2013:160).

$$
t=\frac{r \sqrt{1-2}}{\sqrt{-r^{2}}}
$$

r $\quad$ : koefisien korelasi

n : jumlah yang diteliti

\section{Uji F}

Uji $\mathrm{F}$ hitung digunakan untuk menguji pengaruh secara simultan variabel bebas terhadap variabel tergantungnya. Jika variabel bebas mempunyai pengaruh secara simultan terhadap variabel tergantung maka model persamaan regresi masuk dalam kriteria cocok atau fit. Sebaliknya, jika tidak terdapat pengaruh secara simultan maka masuk kategori tidak cocok atau not fit (Sugiyono, 2015:55). 
$F_{\text {hitung }}=\frac{\frac{R 2}{k}-1}{\frac{\left(1-R^{2}\right)}{(n-K)}}$

Keterangan :

$\mathrm{R}^{2}$ : Korelasi persial yang ditemukan

$\mathrm{n}:$ Jumlah sampel

$\mathrm{K}$ : Jumlah variabel bebas

Rumusan Hipotesis :

$\mathrm{H}_{0}=$ Tidak ada pengaruh antara variabel $\mathrm{X}$ dengan variabel $\mathrm{Y}$

$\mathrm{H}_{\mathrm{a}}=$ Ada pengaruh antara variabel $\mathrm{X}$ dengan variabel

\section{Uji Koefisien Determinasi $\left(\mathbf{R}^{\mathbf{2}}\right)$}

Koefisien Determinasi merupakan ukuran (besaran untuk menyatakan tingkat kekuatan hubungan dalam bentuk persen (\%)) besaran ini dinyatakan dengan notasi $\mathrm{R}$, dimana $\mathrm{R}=\mathrm{r}^{2}$. Jadi, untuk mengetahui seberapa persen besarnya hubungan antara Risk Based Capitad (Variabel X) dengan tingkat profitabilitas (variabel Y) maka menggunakan analisis koefisien determinasi yang diperoleh dengan mengkuadratkan koefisien korelasinya atau dapat dirumuskan sebagai berikut :

Rumus :

$K d=R^{2} \times 100 \%$

Dimana :

$\mathrm{Kd}=$ koefisien determinasi

$\mathrm{R}=$ koefisien determinasi 
HASIL ANALISIS DATA

\section{Uji Regresi Linear Berganda}

\begin{tabular}{|c|c|c|c|c|c|}
\hline \multirow{2}{*}{ Model } & \multicolumn{2}{|c|}{$\begin{array}{l}\text { Unstandardized } \\
\text { Coefficients }\end{array}$} & $\begin{array}{l}\text { Standard } \\
\text { ized }\end{array}$ & \multirow[t]{2}{*}{$\mathrm{t}$} & \multirow[t]{2}{*}{ Sig. } \\
\hline & $B$ & $\begin{array}{l}\text { Std. } \\
\text { Error }\end{array}$ & Beta & & \\
\hline (Constant) & 29,105 & 2,478 & & $\begin{array}{r}11,74 \\
5\end{array}$ & ,000 \\
\hline $\begin{array}{l}\text { Lingkungan } \\
\text { Kerja }\end{array}$ & ,865 & , 136 & 1,720 & 6,376 & ,000 \\
\hline Pelatihan & 147 & ,486 & 110 & ,303 & ,763 \\
\hline $\begin{array}{l}\text { Kualitas_Pro } \\
\text { duk }\end{array}$ & $-1,537$ & ,589 & $-1,247$ & $-2,609$ & ,012 \\
\hline
\end{tabular}

a. Dependent Variable: Produktivitas_Karyawan

Sumber : Output data SPSS 20

\section{Model Summary}

\section{Uji Korelasi Berganda}

\begin{tabular}{|c|c|c|c|c|c|c|c|c|c|}
\hline \multirow{2}{*}{$\begin{array}{l}\text { Mo } \\
\text { del }\end{array}$} & \multirow[t]{2}{*}{$\mathrm{R}$} & \multirow{2}{*}{$\begin{array}{l}R \\
\text { Sq } \\
\text { uar } \\
\text { e }\end{array}$} & \multirow{2}{*}{$\begin{array}{l}\text { Adju } \\
\text { sted } \\
\text { R } \\
\text { Squa } \\
\text { re }\end{array}$} & \multirow{2}{*}{$\begin{array}{l}\text { Std. } \\
\text { Error } \\
\text { of } \\
\text { the } \\
\text { Esti } \\
\text { mate }\end{array}$} & \multicolumn{5}{|c|}{ Change Statistics } \\
\hline & & & & & $\begin{array}{l}\mathrm{R} \\
\text { Squ } \\
\text { are } \\
\text { Cha } \\
\text { nge }\end{array}$ & $\begin{array}{l}\text { F } \\
\text { Cha } \\
\text { nge }\end{array}$ & $\begin{array}{l}\text { df } \\
1\end{array}$ & $\begin{array}{l}\text { df } \\
2\end{array}$ & $\begin{array}{l}\text { Sig. } \\
\text { F } \\
\text { Cha } \\
\text { nge }\end{array}$ \\
\hline 1 & $\begin{array}{l}, 7 \\
6 \\
7 \\
\mathrm{a}\end{array}$ & $\begin{array}{r}58 \\
8\end{array}$ & ,561 & $\begin{array}{r}1,37 \\
0\end{array}$ & ,588 & $\begin{array}{r}21,9 \\
08\end{array}$ & 3 & $\begin{array}{l}4 \\
6\end{array}$ & $\begin{array}{r}, 00 \\
0\end{array}$ \\
\hline
\end{tabular}

a. Predictors: (Constant), Kualitas Produk, Lingkungan_Kerja, Pelatihan

Sumber : Output data SPSS 20

\section{Uji t}

\begin{tabular}{|c|c|c|c|c|c|}
\hline \multirow[t]{2}{*}{ Model } & \multicolumn{2}{|c|}{$\begin{array}{l}\text { Unstandardized } \\
\text { Coefficients }\end{array}$} & \multirow{2}{*}{$\begin{array}{l}\text { Standar } \\
\text { dized } \\
\text { Coeffici } \\
\text { ents } \\
\text { Beta }\end{array}$} & \multirow[t]{2}{*}{ t } & \multirow[t]{2}{*}{ Sig. } \\
\hline & $B$ & $\begin{array}{l}\text { Std. } \\
\text { Error }\end{array}$ & & & \\
\hline (Constant) & 29,105 & 2,478 & & $\begin{array}{r}11,7 \\
45\end{array}$ & ,000 \\
\hline $\begin{array}{l}\text { Lingkungan } \\
\text { _Kerja }\end{array}$ & ,865 & 136 & 1,720 & $\begin{array}{r}6,37 \\
6\end{array}$ & ,000 \\
\hline Pelatihan & , 147 & ,486 & ,110 & ,303 & ,763 \\
\hline $\begin{array}{l}\text { Kualitas_Pr } \\
\text { oduk }\end{array}$ & $-1,537$ & ,589 & $-1,247$ & $\begin{array}{r}2,60 \\
9\end{array}$ & ,012 \\
\hline
\end{tabular}


http://ojs.stie-labuhanbatu.ac.id/index.php/

a. Dependent Variable: Produktivitas_Karyawan

Sumber : Output data SPSS 20

\section{Uji F}

\begin{tabular}{|c|c|c|c|c|c|}
\hline Model & $\begin{array}{l}\text { Sum of } \\
\text { Squares }\end{array}$ & Df & $\begin{array}{l}\text { Mean } \\
\text { Square }\end{array}$ & $F$ & Sig. \\
\hline $\begin{array}{l}\text { Regress } \\
\text { ion }\end{array}$ & 123,349 & 3 & 41,116 & $\begin{array}{r}21,90 \\
8\end{array}$ &, $000^{\mathrm{b}}$ \\
\hline Residua & 86,331 & 46 & 1,877 & & \\
\hline Total & 209,680 & 49 & & & \\
\hline
\end{tabular}

a. Dependent Variable: Produktivitas_Karyawan

b. Predictors: (Constant), Kualitas_Produk,

Lingkungan_Kerja, Pelatihan

Sumber : Output data SPSS 20

\section{Uji Koefisien Determinasi}

Model Summary

\begin{tabular}{|l|l|l|l|l|}
\hline Model & $\mathrm{R}$ & $\begin{array}{l}\mathrm{R} \\
\text { Squar } \\
\mathrm{e}\end{array}$ & $\begin{array}{l}\text { Adjusted } \\
\mathrm{R} \\
\text { Square }\end{array}$ & $\begin{array}{l}\text { Std. Error of } \\
\text { the } \\
\text { Estimate }\end{array}$ \\
\hline 1 &, $767^{\mathrm{a}}$ &, 588 &, 561 & 1,370 \\
\hline
\end{tabular}

a. Predictors: (Constant), Kualitas_Produk,

Lingkungan_Kerja, Pelatihan

Sumber : Output data SPSS 20

\section{PEMBAHASAN}

1. Dari hasil penelitian dapat diperoleh kesimpulan bahwa dari perhitungan analisis regresi linier sederhana mempunyai koefisien

$\mathrm{Y}=29,105+0,865 \mathrm{X}_{1}+0,147 \mathrm{X}_{2}+-1,537 \mathrm{X}_{3}$

Konstanta sebesar 29,105 artinya jika lingkungan kerja $\left(\mathrm{X}_{1}\right)$, Pelatihan $\left(\mathrm{X}_{2}\right)$ dan kualitas produk $\left(\mathrm{X}_{3}\right)$ nilainya adalah 0 , maka produktivitas karyawan $(\mathrm{Y})$ nilainya positif yaitu sebesar 29,105.

2. Dari tabel uji koefisien korelasi parsial diketahui bahwa nilai koefisien korelasi parsial (r) di dapat dari nilai korelasi antara variabel lingkungan kerja, Pelatihandan kualitas produk dan variabel produktivitas karyawan sebesar 0,767 hal ini menunjukan ada pengaruh yang signifikan antara lingkungan kerja, Pelatihandan kualitas produk dan variabel produktivitas karyawan karena nilai ( $\mathrm{r}$ ) mendekati angka 1.

3. Dari hasil uji $\mathrm{t}$ di peroleh $\mathrm{t}_{\text {hitung }}>\mathrm{t}_{\text {tabel }}$ dengan nilai $6,376>2,012$ maka $\mathrm{H}_{0}$ di tolak, yang berarti bahwa ada pengaruh yang signifikan antara variabel lingkungan kerja $\left(\mathrm{X}_{1}\right)$ terhadap produktivitas karyawan $(Y)$. Diperoleh $t_{\text {hitung }}>t_{\text {tabel }}$ dengan nilai $0,303<2,012$ 
maka $\mathrm{H}_{0}$ di terima, yang berarti bahwa tidak ada pengaruh yang signifikan antara variabel Pelatihan $\left(\mathrm{X}_{2}\right)$ terhadap produktivitas karyawan $(\mathrm{Y})$. Diperoleh $t_{\text {hitung }}>\mathrm{t}_{\text {tabel }}$ dengan nilai $-2,609>2,012$ maka $\mathrm{H}_{0}$ di terima, yang berarti bahwa tidak ada pengaruh yang signifikan antara variabel kualitas produk $\left(\mathrm{X}_{3}\right)$ terhadap produktivitas karyawan (Y).

4. Dari hasil uji $\mathrm{F}$ diperoleh $\mathrm{F}_{\text {hitung }}>\mathrm{F}_{\text {tabel }}$ dengan nilai 21,908 $>$ 3,20 maka $\mathrm{H}_{0}$ ditolak , yag berarti ada pengaruh yang signifikan antara variabel bebas lingkungan kerja $\left(\mathrm{X}_{1}\right)$, Pelatihan $\left(\mathrm{X}_{2}\right)$ dan kualitas produk $\left(\mathrm{X}_{3}\right)$ secara simultan atau bersama-sama terhadap produktivitas karyawan (Y).

5. Dari hasil diperoleh koefisien determinasi $\left(\mathrm{R}^{2}\right)$ sebesar 0,767 , dari $\left(\mathrm{R}^{2}\right)$ tersebut dapat ditarik kesimpulan bahwa nilai ini menunjukkan bahwa kekuatan hubungan antara variabel bebas dan variabel terikat adalah kuat, selain itu dapat diperoleh pula iinformasi berapa koefisien determinasi adalah sebesar $76 \%$ nilai ini menunjukkan bahwa kontribusi variabel bebas terhadap variabel terikat secara simultan adalah sebesar $76 \%$ sedangkan $24 \%$ sisanya dipengaruhi oleh variabel lain diluar variabel lingkungan kerja, Pelatihandan kualitas produk.

\section{KESIMPULAN DAN SARAN KESIMPULAN}

Dari hasil analisis data, maka hasil dari penelitian ini dapat disimpulkan sebagai berikut :

1. Secara parsial variabel lingkungan kerja $\left(\mathrm{X}_{1}\right)$ berpengaruh secara signifikan terhadap produktifitas karyawan (Y) Home Industri (Konveksi Kerudung) Vila Collection Laren Lamongan karena mempunyai nilai $\mathrm{r}_{\mathrm{x} 1 \mathrm{y}}=6,376$ dan $\mathrm{t}_{\mathrm{hitung}}$ yang lebih besar dibandingkan dengan nilai $t_{\text {tabel }}$ yaitu sebesar $6,376>2,012$. Sedangkan Pelatihan $\left(X_{2}\right)$ tidak berpengaruh signifikan terhadap produktivitas karyawan (Y) Home Industry Vila Collection karena nilai $\mathrm{r}_{\mathrm{x} 2 \mathrm{y}}=0,303$ dan nilai $t_{\text {hitung }}$ lebih kecil dari pada $t_{\text {tabel }}$ yaitu sebesar $0,303<2,012$. Sedangkan kualitas produk $\left(\mathrm{X}_{3}\right)$ tidak berpengaruh signifikan terhadap produktivitas karyawan (Y) Home Industry Vila Collection karena nilai $r_{\mathrm{x} 2 \mathrm{y}}=-2,609$ karena $t_{\text {hitung }}$ lebih kecil dari pada $t_{\text {tabel }}$ yaitu sebesar $-2,609>2,012$.

2. Secara simultan variabel bebas lingkungan kerja $\left(X_{1}\right)$, Pelatihan $\left(X_{2}\right)$ dan kualitas produk $\left(\mathrm{X}_{3}\right)$ berpengaruh secara signifikan terhadap produktivitas karyawan (Y) Home Industry (Konveksi Kerudung) Vila Collection Laren Lamongan Hal ini dibuktikan dengan besarnya nilai $F_{\text {hitung }}$ dibandingkan dengan $F_{\text {tabel }}$ yaitu 21,908>3,20 dan nilai determinasinya 0,767 .

3. Dilihat dari koefisien regresi linear berganda konstanta sebesar 29,105 artinya jika lingkungan kerja $\left(\mathrm{X}_{1}\right)$ nilainya adalah 0 , maka produktivitas karyawan (Y) nilainya positif yaitu sebesar 29,105. Koefisien variabel lingkungan kerja $\left(\mathrm{X}_{1}\right)$ sebesar 0,865 koefisien bernilai positif artinya terjadi hubungan positif antara lingkungan kerja dengan produktivitas karyawan. Koefisien variabel Pelatihan $\left(\mathrm{X}_{2}\right)$ sebesar 0,147 koefisien bernilai positif artinya terjadi hubungan positif antara Pelatihandengan produktivitas karyawan. Koefisien variabel kualitas produk $\left(\mathrm{X}_{3}\right)$ sebesar $-1,537$ koefisien bernilai 
negatif artinya tidak terjadi hubungan positif antara kualitas produk dengan produktivitas karyawan.

\section{SARAN}

Setelah penulis mempelajari keadaan yang terjadi pada lingkungan di Home Industry (Konveksi Kerudung) Vila Collection Laren Lamongan, maka pada kesempatan ini penulis akan mengemukakan saran-saran yang kiranya dapat bermanfaat atau dapat dijadikan bahan pertimbangan guna meningkatkan produktivitas karyawan di Home Industry (Konveksi Kerudung) Vila Collection Laren Lamongan :

1. Diharapkan untuk dapat meningkatkan lingkungan kerja, Pelatihandan kualitas produk Home Industry (Konveksi Kerudung) Vila Collection Laren Lamongan sehingga nantinya para karyawan merasa nyaman sehingga karyawan dapat melakukan aktivitas produksi dengan lebih semangat.

2. Diharapkan para karyawan Home Industry (Konveksi Kerudung) Vila Collection Laren Lamongan dapat menjaga kebersihan lingkungan kerja, memelihara penerangan ditempat kerja dan juga lebih peka terhadap lingkungan, agar dapat tercipta lingkungan kerja yang berkualitas.

3. Kebijakan dan peraturan yang telah di buat oleh pihak Home Industry, hendaknya di patuhi dan di laksanakan secara optimal dan berkelanjutan.

4. Untuk penelitian selanjutnya hendaknya memperluas sampel penelitiannya bukan hanya para karyawan Home Industry (Konveksi Kerudung) Vila Collection saja tetapi dapat mengambil sampel lainnya sehingga hasil penelitiannya dapat lebih tergeneralisasi.

\section{DAFTAR PUSTAKA}

Budiyono, Amirul Haris. 2013. Pengantar Manajemen. Yogyakarta: Graha Ilmu

Handoko,T. Hani.2011. Dasar-Dasar Manajemen Produksi Dan Operasi. Cetakan keenambelas. Yogyakarta: BPPB

Henry, Simamora. 2004. Manajemen Sumber Daya Manusia. Edisi Ke-3. STIE YKPN. Yogyakarta

Mangkunegara, A. A. Anwar Prabu. 2006. Perencanaan dan Pengembangan SDM. Bandung: Refika Aditama

Simanjuntak, Payaman J. 2011. Manajemen Dan Evaluasi Kerja. Jakarta: Fakultas Ekonomi UI

Soedarmayanti. 2011. Metodologi Penelitian. Bandung: CV. Mandar Maju

Sofyan Siregar. 2013. Metode Penelitian Kuantitatif. Jakarta: Prenada Media Group

Sugiyono. 2015. Metode Penelitian Pendidikan. Bandung: Alfabeta

Veithzal Rivai, 2011. Managemen Sumber Daya Untuk Perusahaan. PT. Raja Grafindo Persada, Jakarta. 
